Available Online at ESci Journals

Journal of Plant Breeding and Genetics

ISSN: 2305-297X (Online), 2308-121X (Print)

http://www.escijournals.net/JPBG

\title{
AMMI AND GGE BIPLOT ANALYSIS OF LINSEED (LINUM USITATISSIMUM L.) GENOTYPES IN CENTRAL AND SOUTH-EASTERN HIGHLANDS OF ETHIOPIA
}

Adane C. Chobe*, Abebe D. Ararsa

Kulumsa Agricultural Research Center, Ethiopian Institute of Agricultural Research P.O. Box 489, Asella, Ethiopia.

\section{A B S T R A C T}

Twelve linseed genotypes were evaluated in 13 environments during the main cropping season in central highlands of Ethiopia. The objective of the study was to determine the magnitude and pattern of $G \times E$ interaction and yield stability in linseed genotypes. The study was conducted using a randomized complete block design with 3 replications. Genotype $\times$ environment interaction and yield stability were estimated using the additive main effects and multiplicative interaction and site regression genotype plus genotype $\times$ environment interaction biplot. Pooled analysis of variance for seed yield showed significant $(\mathrm{p} \leq 0.001)$ differences among the genotypes, environments and $\mathrm{G} \times \mathrm{E}$ interaction effects. This indicated that the genotypes differentially responded to the changes in the test environments or the test environments differentially discriminated the genotypes or both. Environment effect was responsible for the greatest part of the variation, followed by $\mathrm{G} \times \mathrm{E}$ interaction and genotype effects, indicating spatial and temporal replications of linseed yield trials. The first three multiplicative component terms of AMMI were found to be significant. The first two multiplicative component terms sum of squares, with their cumulative degrees of freedom of 44 , explained $62.9 \%$ of the interaction sum of squares. No single variety showed superior performance in all environments but CI-1525 demonstrated top ranking at six of the thirteen environments. The application of AMMI and GGE biplots facilitated the visual comparison and identification of superior genotypes, thereby supporting decisions on variety selection and recommendation in different environments.

Keywords: AMMI, GGE biplot, Linseed, Stability, Ethiopia.

\section{INTRODUCTION}

Linseed (Linum usitatissimum L., $\mathrm{n}=15$ ) is one of the oldest oilseeds cultivated for food and fiber (Lay and Dybing, 1989). It is a major oilseed crop produced in the South Eastern and Central Highlands of Ethiopia followed by Noug. It is the second major after Noug and the third major after Noug and sesame in the Oromia region and Ethiopia, respectively (CSA, 2016). During 2015/16 cropping season, 746,581 subsistence farmers allocated $85,415.67$ hectares of land for linseed production and produced $88,551.14$ tons of linseed with an average yield of $1.04 \mathrm{t} / \mathrm{ha}$ (CSA, 2016). It occupies $10 \%$ of the total area cultivated for oilseeds with $11.3 \%$ of the total annual oilseeds production in the country. Linseed is widely cultivated in higher elevations of Ethiopia where frost is a threat for other oilseeds

\footnotetext{
* Corresponding Author:

Email: adecc2008@gmail.com

(C) 2018 ESci Journals Publishing. All rights reserved.
}

(Getinet and Nigussie, 1997). It is an important precursor crop for cereal, pulse and potato crops in Southeastern highlands of Ethiopia (Abebe and Adane, 2015). Typically, linseed consists of approximately $40 \%$ fat, $28 \%$ dietary fiber, $21 \%$ protein, $4 \%$ ash, and $6 \%$ carbohydrates (Vaisey-Genser and Morris, 2010). Linseed has wide uses: it is a source of food, feed, fiber, oil, medicine, and industrial raw material and export commodity. Linseed possesses very healthy fatty acids (linoleic-Omega 6 and alpha-linolenic acids or Omega 3). Linseed cake is rich in microelements, vitamins, dietary cellulose, proteins (up to 38\%) (Altai, 2010). Despite its importance, however, the productivity of linseed has been very low as compared to cereal and pulse crops and frequently affected by environment. Linseed breeding research in Ethiopia has started in the early 1960s when a number of genotypes were tested by the then Haile Selassie I University at Debrezeit Research Station (Bantayehu, 1965). So far, several varieties of 
linseed have been released in Ethiopia by national and regional research institutions (MoANR, 2016). The breeding program of linseed in Ethiopia focusses mainly on improving seed yield and oil content with resistance to major linseed diseases, namely wilt (Fusarium oxysporum), pasmo (Septoria lincola) and powdery mildew (Odium spp). In addition to its yielding potential and better resistance to major diseases; linseed variety needs to have stable performance and broad adaptation over a wide range of environments.

However, crop genotypes grown in different environments would frequently encounter significant fluctuations in yield performance, particularly when the growing environments are distinctly different, the test genotypes differentially respond to changes in the growing environments or both. The fluctuation of crop performance with changing environments, technically termed as genotype $\times$ environment $(G \times E)$ interaction, potentially presents limitations on selection and recommendation of varieties for target set of environments, particularly when it is a "crossover" type or when rank order changes among the genotypes are involved (Navabi et al., 2006). GEI is a universal phenomenon when different genotypes are tested in a number of environments and is an important issue for plant breeders and agronomists to predict cultivar behaviour in different locations across different years prior to any cultivar recommendation. Usually, environment expresses most of the total yield variations, while genotype and Genotype $\times$ Environment Interaction (GEI) are less effective (Dehghani et al., 2008; Yan and Kang, 2003).

Different methods have been employed in trying to realize genotypes reaction in different situations. But it is often difficult to determine the pattern of genotypic response across locations or seasons without the help of a graphical display of the data (Yan et al., 2001). Biplot analysis provides a solution to the above problem as it displays the two-way data and allows visualization of the interrelationship among environments, genotypes, and interactions between genotypes and environments. Two types of biplots, the AMMI biplot (Gauch, 1988; Gauch and Zobel, 1997) and the site regression (SREG) genotype plus genotype $\mathrm{x}$ environment interaction (GGE) biplot (Ma et al., 2004; Yan et al., 2000) have been used widely to visualize genotype $\times$ environment interaction. AMMI is a multivariate tool, which was highly effective for the analysis of multi environment trials and in the recent years, this method has often been used by international agricultural development agencies (Grüneberg et al., 2005). The most recent method, the GGE (genotype main effect (G) plus G x E interaction) biplot model, provides breeders a more complete and visual evaluation of all aspects of the data by creating a biplot that simultaneously represents mean performance and stability, as well as identifying mega-environments (Ding et al., 2007; Yan and Kang, 2003). Previous works that has been reported on linseed genotypes performance stability in Ethiopia were limited and either based on multivariate statistics such as AMMI (Adugna and Labuschagne, 2002; Ersullo et al., 2016) or have been used only few regression/parametric and non-parametric approaches (Adugna and Labuschagne, 2003). In this experiment, we attempted to apply AMMI and sites regression GGE biplot statistical model for determination of the magnitude and pattern of $G$ $\times$ E interaction effects and performance stability of seed yield in elite and released linseed genotypes.

\section{MATERIALS AND METHODS}

Testing Locations and Testing Genotypes: Twelve linseed genotypes (seven nationally released varieties and five elite materials) (Table 2) were evaluated in 13 environments (seven locations in 2008 and six locations in 2009) during the main cropping season (June to December). The locations are representative of linseed varieties testing sites of central and South-eastern parts of Ethiopia: (I) Holetta representing the highland areas of West Shewa Zone, (II) Kulumsa representing mid altitudes of Arsi Zone, (III) Bekoji representing the high rainfall and long growing season areas of Arsi, (IV) Meraro representing the high rainfall and long growing season areas and areas with frost problem of Arsi, (V) Asasa representing mid altitudes having relatively short growing season with terminal moisture stress of Arsi, (VI) Kofele similar with Bekoji but sometimes has terminal frost problem in Arsi, (VII) Sagure representing vertisol areas of Arsi and (VIII) Arsi-Robe similarly representing typical vertisol areas Table 1).

Experimental Layout and Design: The genotypes were evaluated in a randomized complete block design with three replications. Plot size of six rows of five meters length and $20 \mathrm{~cm}$ spacing between rows was used. The paths between blocks were $2 \mathrm{~m}$. Each entry was sown at a seed rate of $25 \mathrm{~kg} / \mathrm{ha}$ by hand drilling the seeds in the rows. Fertilizer rate of $23 / 23 \mathrm{~kg} / \mathrm{ha} \mathrm{N} / \mathrm{P}_{2} \mathrm{O}_{5}$ was used for all sites at planting, except for Kulumsa where fertilizer was not applied. 
Table 1. Descriptions of the test locations.

\begin{tabular}{|c|c|c|c|c|c|c|c|c|}
\hline \multirow{2}{*}{ Locations } & \multicolumn{2}{|c|}{ Geographical Position } & \multirow{2}{*}{$\begin{array}{l}\text { Altitude } \\
\text { (m.a.s.l.) }\end{array}$} & \multirow{2}{*}{$\begin{array}{c}\text { Average } \\
\text { rainfall }\end{array}$} & \multicolumn{2}{|c|}{ Temperature $\left({ }^{\circ} \mathrm{C}\right)$} & \multirow{2}{*}{ Soil Type } & \multirow{2}{*}{$\begin{array}{l}\text { Soi } \\
\mathrm{pH}\end{array}$} \\
\hline & Latitude & Longitude & & & Min & Max & & \\
\hline Arsi Robe & $07^{\circ} 53^{\prime} 02^{\prime \prime} \mathrm{N}$ & $39^{\circ} 37^{\prime} 40^{\prime \prime} \mathrm{E}$ & 2440 & 796 & 6.0 & 22.1 & Vertisol & 5.6 \\
\hline Asasa & $07^{\circ} 07^{\prime} 228^{\prime \prime} \mathrm{N}$ & $39^{\circ} 11^{\prime} 932^{\prime \prime} \mathrm{E}$ & 2360 & 620 & 5.8 & 23.6 & Chernozens & 6.2 \\
\hline Bekoji & $07^{\circ} 32^{\prime} 629^{\prime \prime} \mathrm{N}$ & $39^{\circ} 15^{\prime} 360^{\prime \prime} \mathrm{E}$ & 2780 & 1010 & 7.9 & 18.6 & Nitosol & 5.0 \\
\hline Holeta & $09^{\circ} 03^{\prime} 414^{\prime \prime} \mathrm{N}$ & $38^{\circ} 30^{\prime} 436^{\prime \prime} \mathrm{E}$ & 2400 & 976 & 6.1 & 22.4 & Nitosol & 4.9 \\
\hline Kofele & $07^{\circ} 04^{\prime} 28^{\prime \prime} \mathrm{N}$ & $38^{\circ} 47^{\prime} 11^{\prime \prime} \mathrm{E}$ & 2660 & 1211 & 7.1 & 18 & Loam & 5.2 \\
\hline Kulumsa & $08^{\circ} 01^{\prime} 10^{\prime \prime} \mathrm{N}$ & $39^{\circ} 09^{\prime} 11^{\prime \prime} \mathrm{E}$ & 2200 & 820 & 10.5 & 22.8 & Luvisol & 6.0 \\
\hline Meraro & $07^{\circ} 24^{\prime} 27^{\prime \prime} \mathrm{N}$ & $39^{\circ} 14^{\prime} 56^{\prime \prime} \mathrm{E}$ & 2980 & 878 & 5.7 & 18.1 & Alfisol & 5.0 \\
\hline Sagure & $07^{\circ} 44^{\prime} 47^{\prime \prime} \mathrm{N}$ & $39^{\circ} 09^{\prime} 24^{\prime \prime} \mathrm{E}$ & 2430 & 850 & NA & NA & Vertisol & 5.6 \\
\hline
\end{tabular}

Table 2. Descriptions of 12 linseed genotypes tested across thirteen environments during 2008 and 2009 cropping seasons.

\begin{tabular}{cllclc}
\hline No & Genotype & Source & Year of release & Origin & Seed color \\
\hline 1 & CI-1525 & HARC & 1984 & Europe & Brown \\
2 & CI-1652 & HARC & 1984 & Europe & Brown \\
3 & Chilallo & HARC & 1992 & Local germplasm & Brown \\
4 & Belay-96 & HARC & 1996 & Cross & Brown \\
5 & Berene & HARC & 2001 & Local germplasm & Brown \\
6 & Tole & HARC & 2004 & Cross & Brown \\
7 & Kulumsa-1 & KARC & 2006 & A selection from Chilallo & Brown \\
8 & Chilallo x Omega/4B & KARC & Elite material & Cross & Brown \\
9 & Chilallo x PGRC/E 10306/4Y & KARC & $"$ & Cross & Yellow \\
10 & Chilallo x Omega/13Y & KARC & $"$ & Cross & Yellow \\
11 & CI-1525 x Omega/1Y & KARC & $"$ & Cross & Yellow \\
12 & CI-1525 x Omega/14Y & KARC & $"$ & Cross & Yellow \\
\hline
\end{tabular}

Other agronomic and cultural practices were uniformly carried out as per recommendations for all sites and plots. For data analysis, seed yield was measured from a net plot size of $4 \mathrm{~m}^{2}$ and converted into $\mathrm{kg} \mathrm{ha}^{-1}$ at $7 \%$ standard seed moisture content.

Data Analysis: The seed yield data was subjected to analysis of variance using the SAS Statistical Package (SAS, 2002). Variance homogeneity was tested, and combined analysis of variance was done using the General Linear Model (PROC GLM) procedure to partition the total variation into components due to genotype (G), environment (E) and $\mathrm{G} \times \mathrm{E}$ interaction effects. The following model was used for combined ANOVA:

$$
\mathrm{Y}_{\mathrm{ij}} \mathrm{k}=\mu+\mathrm{G}_{\mathrm{i}}+\mathrm{E}_{\mathrm{j}}+\mathrm{GE}_{\mathrm{ij}}+\mathrm{B}_{\mathrm{k}(\mathrm{j})}+\epsilon_{\mathrm{ijk}}
$$

where, $Y_{\mathrm{ijk}}$ is an observed value of genotype $i$ in block $k$ of environment $j ; \mu$ is a grand mean; Gi is effect of genotype $i ; \mathrm{E}_{j}$ is an environmental effect; $\mathrm{GE}_{\mathrm{ij}}$ is the interaction effect of genotype $i$ with environment $j$; $\mathrm{B}_{\mathrm{k}(\mathrm{j})}$ is the effect of block $k$ in environment $j$; $\epsilon_{\mathrm{ijk}}$ is an error effect of genotype $i$ in block $k$ of environment $j$. Genotype was regarded as a fixed effect while the environment was regarded as a random effect. The main effect of $E$ was tested against the replication within the environment (R/E) as Error 1, the main effect of $G$ was tested against the $G \times E$ interaction, and the $G \times E$ interaction was tested against pooled error as Error 2. Separation of the main effect was done using Duncan's Multiple Range Test at 5\% probability level. AMMI analysis and AMMI2 GE biplot was done using the SAS program following the procedures of (Hernandez and Crossa, 2000) as modified by (Burgueño et al., 2001). AMMI1 graph was done using the scatter plot program of Excel spreadsheet. The following AMMI linear-bilinear model was used for analyses of $\mathrm{G} \times \mathrm{E}$ interaction and performance stability:

$$
\mathrm{Y}_{\mathrm{ij}}=\mu+\tau_{\mathrm{i}}+\delta_{\mathrm{j}}+\sum^{\mathrm{t}} \mathrm{k}_{\mathrm{k}}{ }_{1} \lambda_{\mathrm{k}} \alpha_{\mathrm{ik}} \gamma_{\mathrm{jk}}+\dot{\varepsilon}_{\mathrm{ij}}
$$

where, $\bar{y}_{i j}$ is the mean of the $i^{\text {th }}$ cultivar in the $j^{\text {th }}$ environments; $\mu$ is the overall mean; $\tau_{i}$ is the genotypic effect; $\delta_{\mathrm{j}}$ is the environment effect; $\lambda_{\mathrm{k}}\left(\lambda_{1} \geq \lambda_{2} \geq \ldots \geq \lambda_{\mathrm{t}}\right)$ are 
scaling constants (singular values) that allow the imposition of orthonormality constraints on the singular vectors for genotypes, $\alpha_{\mathrm{ik}}=\left(\alpha_{1 \mathrm{k}} \ldots, \alpha_{\mathrm{gk}}\right)$ and sites, $\gamma_{\mathrm{jk}}=$ $\left(\gamma_{1 \mathrm{k}} \ldots, \gamma_{\mathrm{ek}}\right)$, such that $\sum_{\mathrm{i}} \alpha^{2_{i k}}=\sum_{\mathrm{j}} \gamma^{2}{ }_{\mathrm{jk}}=1$ and $\sum_{\mathrm{i}} \alpha_{\mathrm{ik}} \alpha_{\mathrm{ik}}=\sum_{\mathrm{j}}$ $\gamma_{\mathrm{jk}} \gamma_{\mathrm{jk}}=0$ for $\mathrm{k} \neq \mathrm{k}$; $\alpha_{\mathrm{ik}}$ and $\gamma_{\mathrm{jk}}$ for $\mathrm{k}=1,2,3, \ldots$ are called "primary," "secondary," "tertiary,". . . etc. effects of genotypes and environments, respectively; $\dot{\varepsilon}_{\mathrm{ij}}$. is the residual error assumed to be NID $\left(0, \sigma^{2} / r\right)$ (where, $\sigma^{2}$ is the pooled error variance and $r$ is the number of replication). Least square estimates of the multiplicative (bilinear) parameters in the $\mathrm{k}^{\text {th }}$ bilinear term were obtained as the $\mathrm{k}^{\text {th }}$ component of the deviations from the additive (linear) part of the model. In the AMMI model, only the $G \times E$ interaction term was absorbed in the bilinear terms, whereas in the SREG model, the main effects of genotypes $(G)$ plus the $G \times E$ interaction were absorbed into the bilinear terms.

\section{RESULTS AND DISCUSSION}

Genotypic Performance: The AMMI ANOVA for seed yield $\left(\mathrm{kg} \mathrm{ha}^{-1}\right)$ of the 12 linseed genotypes across the 13 environments indicated that the environments, the genotypes and GEI effects were significantly different ( $\mathrm{p}<0.001$ ). Several authors (Jacobsz et al., 2015; Tadesse, 2017) reported similar results suggesting the existence of wide variability among genotypes, among environments and the possibility of selection for stable genotypes. The present results also revealed that the environments which accounted for $67.4 \%$ of the total yield variation significantly influenced the yielding ability of the linseed genotypes. A large yield variation, explained by environments, indicated that the environments were diverse and a major part of the variation in seed yield can result from environmental Table 3. AMMI analysis of variance for seed yield $\left(\mathrm{kg} \mathrm{ha}^{-1}\right)$ of 12 linseed genotypes evaluated at 13 environments of Ethiopia.

\begin{tabular}{|c|c|c|c|c|c|c|}
\hline \multicolumn{2}{|c|}{ Source } & $\mathrm{DF}$ & Sum of squares & Mean square & F-value & \% explained \\
\hline \multicolumn{2}{|l|}{ Model } & 181 & 105665295 & 583786 & $8.52^{* * *}$ & \\
\hline \multicolumn{2}{|c|}{ Environment (E) } & 12 & 71192353 & 5932696 & $86.63^{* * *}$ & 67.4 \\
\hline \multicolumn{2}{|l|}{ Genotype (G) } & 11 & 11042844 & 1003895 & $14.66^{* * *}$ & 10.5 \\
\hline \multirow[t]{4}{*}{ GxE } & & 132 & 19209645 & 145528 & $2.12^{* * *}$ & 18.2 \\
\hline & AMMI1 & 23 & 7747918 & 336866 & $4.92^{* * *}$ & 40.3 \\
\hline & AMMI2 & 21 & 4341223 & 206725 & $3.02^{* * *}$ & 22.6 \\
\hline & AMMI3 & 19 & 3155894 & 166100 & $2.43^{* *}$ & 16.4 \\
\hline \multirow{2}{*}{\multicolumn{2}{|c|}{$\begin{array}{l}\text { Residual } \\
\text { Pooled error }\end{array}$}} & 81 & 3966560 & 309339 & $4.52 \mathrm{~ns}$ & 20.7 \\
\hline & & 286 & 19586929 & 68486 & & \\
\hline
\end{tabular}

$(a)^{* * *}$ is significant at 0.001 probability level; $(b)^{* *}$ is significant at 0.01 probability level; $(c) D F=$ degrees of freedom; $(d) R^{2}=$ coefficient of determination; $(e) C V=$ coefficient of variation. changes (Table 3), followed by genotype $\mathrm{x}$ environments interaction and genotypic effects accounting $18.2 \%$ and $10.5 \%$, respectively. Similar results have been reported for different linseed genotypes evaluated in different environments and countries (Berti et al., 2010; Jacobsz et al., 2015; Tadesse, 2017). The GEI effect is almost twice the genotypic effects indicating the existence of differential response of the genotypes to changes in growing environments and the discriminating ability of the environments. The average environmental seed yield across genotypes ranged from the lowest of $748 \mathrm{~kg} \mathrm{ha}^{-1}$ at Arsi Robe in 2009 to the highest of $2270 \mathrm{~kg} \mathrm{ha}^{-1}$ at Meraro in 2008, with a grand mean of $1631 \mathrm{~kg} \mathrm{ha}^{-1}$ (Table 4). The genotypes average seed yield across environments ranged from the lowest of $1392 \mathrm{~kg} \mathrm{ha}^{-1}$ for CI-1525 x OMEGA/1Y to the highest of $1953 \mathrm{~kg} \mathrm{ha}^{-1}$ for CI-1525 (Table 4). Linseed variety, CI-1525, ranked first at six of the 13 environments (Bekoji in 2008, Holeta in 2008, Kofele in 2008, Meraro in 2008, Bekoji in 2009 and Kulumsa in 2009). However, seven different genotypes ranked first in the remaining seven environments. CI-1525 produced the best seed yield (3080 kg ha-1) ) at the highest yielding environment, Meraro in 2008. On the other hand, CI-1652 produced the best seed yield (927 $\mathrm{kg} \mathrm{ha}^{-1}$ ) at the lowest yielding environment, Arsi Robe in 2009 (Table 4). This ranking difference among the genotypes across the environments depicts that there is a cross over type of genotype $\mathrm{x}$ environment interaction (Kaya et al., 2006). The genotype $\mathrm{x}$ environment interaction (GEI) was partitioned into interaction principal component axis (IPCA) (Table 3). 
Table 4. Mean seed yield performance of 12 linseed genotypes evaluated across thirteen environments.

\begin{tabular}{|c|c|c|c|c|c|c|c|c|c|c|c|c|c|c|c|}
\hline Code & Name & E1 & E2 & E3 & E4 & E5 & E6 & E7 & E8 & E9 & E10 & E11 & E12 & E13 & Mean \\
\hline G1 & CI-1525 & 1951 & 1942 & 2099 & 2065 & 1578 & $\underline{3080}$ & 757 & 1342 & 2901 & 1695 & 2479 & 1772 & 1732 & $1953^{a}$ \\
\hline G2 & CI-1652 & 1438 & 1628 & 1825 & 1512 & 640 & 2338 & $\underline{927}$ & 975 & 2238 & 1660 & 1835 & 1537 & 1726 & $1560^{c d}$ \\
\hline G3 & CHILALLO & 1533 & 1431 & 1632 & 1298 & 1152 & 1710 & $\overline{801}$ & 1358 & 1915 & 1608 & 1900 & 1295 & 1605 & $1480^{\text {de }}$ \\
\hline G4 & BELAY-96 & 1662 & 1582 & 1828 & 1255 & 1238 & 2138 & 881 & 1505 & 2435 & 1847 & 1867 & $\underline{2035}$ & 1845 & $1701^{b}$ \\
\hline G5 & BERENE & 1738 & 1654 & 1978 & 1715 & 1368 & 2164 & 864 & 1518 & 2204 & 1792 & 2005 & 1748 & 1904 & $1742^{b}$ \\
\hline G6 & TOLE & 1514 & 1837 & 1966 & 1727 & $\underline{1617}$ & 2444 & 728 & 1577 & 2079 & 1644 & 1814 & 1578 & 1596 & $1702^{b}$ \\
\hline G7 & KULUMSA-1 & 1458 & 1900 & 2051 & 1863 & $\overline{641}$ & 2289 & 823 & 1612 & 2539 & 1931 & 2235 & 1517 & 1788 & $1742^{b}$ \\
\hline G8 & CHILALLO $\times$ OMEGA/4B & 1421 & 1864 & 2003 & 1973 & 874 & 2685 & 697 & 1283 & 2489 & $\overline{1749}$ & 2330 & 1688 & 1504 & $1736^{b}$ \\
\hline G9 & CHILALLOXPGRCE10306/4Y & 1730 & 1383 & 1702 & 1761 & 1603 & 2015 & 556 & 1355 & 1961 & 1623 & 1984 & 1625 & 1681 & $1614^{\mathrm{bc}}$ \\
\hline G10 & CHILALLO x OMEGA/13Y & 1462 & 1551 & 1366 & 1667 & 1155 & 2090 & 585 & 1217 & 2193 & 1354 & 1840 & 1410 & 1417 & $1485^{\text {de }}$ \\
\hline G11 & CI-1525 x OMEGA/1Y & 1728 & 1334 & 1177 & 1217 & 815 & 2013 & 666 & $\underline{1724}$ & 1936 & 1367 & 1425 & 1442 & 1257 & $1392^{e}$ \\
\hline \multirow[t]{4}{*}{ G12 } & CI-1525 x OMEGA/14Y & 1993 & 1311 & 1173 & 901 & 798 & 2275 & 691 & 1687 & 2011 & 1494 & 1710 & 1511 & 1504 & $1466^{\mathrm{de}}$ \\
\hline & Minimum & 746 & 1015 & 1060 & 709 & 424 & 1240 & 494 & 802 & 1533 & 1125 & 1295 & 856 & 1138 & 1392 \\
\hline & Maximum & 2394 & 2179 & 2605 & 2554 & 2173 & 3500 & 1147 & 2156 & 3143 & 2248 & 2800 & 2384 & 2111 & 1953 \\
\hline & Mean & $1636^{c d}$ & $1618^{\mathrm{cd}}$ & $1733^{c}$ & $1580^{d}$ & $1123^{f}$ & $2270^{a}$ & $748 \mathrm{~g}$ & $1429^{e}$ & $2242^{a}$ & $1647^{c d}$ & $1952^{b}$ & $1597 \mathrm{~cd}$ & $1630^{\text {cd }}$ & 1631 \\
\hline 1631 & CV (\%) & 21.8 & 8.4 & 16.4 & 19.3 & 21.8 & 15.8 & 20.8 & 16.6 & 10.2 & 13.6 & 11.7 & 21.1 & 11.2 & 16.04 \\
\hline
\end{tabular}

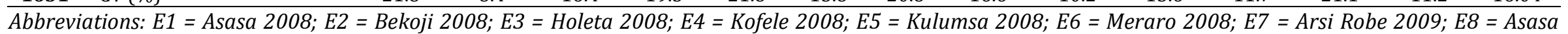
2009; E9 = Bekoji 2009; E10 = Holeta 2009; E11 = Kulumsa 2009; E12 = Meraro 2009 and E13 = Sagure 2009.

The IPCA 1 and IPCA 2 scores were highly significant $(\mathrm{p}<0.001)$ explaining a total of $62.9 \%$ of the variability relating to GEI each accounting $40.3 \%$ and $22.6 \%$ with a degree of freedoms of 23 and 21, respectively. The IPCA 3 was also significant at $\mathrm{p}<0.01$, accounting for $16.4 \%$ of the variability with a degree of freedom of 19 . The extracted IPCAs are capable of providing adequate information on the interaction effects but their degree decreases from the first to the last IPCAs. Thus, the first two best explain the interaction sums of squares (Jacobsz et al., 2015; Zobel et al., 1988).

AMMI 1 Biplot Display: Genotypes and environments additive main effects against their respective first multiplicative term (IPC1) are depicted as triangle and rectangle respectively, on a plane in AMMI1 biplot (Figure 1). In the AMMI 1 biplot, the usual interpretation of biplot is that the displacements along the abscissa indicate differences in main (additive) effects, whereas displacements along the ordinate indicate differences in interaction effects. Genotypes that group together have similar adaptation while environments which group together influences the genotypes in the same way (Kempton, 1984). The best adapted genotype can plot far from the environments. If a genotype or an environment has an IPCA1 score of nearly zero, it has small interaction effects and considered as stable whereas the larger scores depict more specific adaptation to environments with IPC1 scores of the same sign (Ebdon and Gauch, 2002). When a genotype and environment have the same sign on the PCA axis, their interaction is positive and if different, their interaction is negative. Accordingly, CHILALLO $\mathrm{x}$ OMEGA/13Y is the most stable variety with its IPC1 score very close to zero indicating its less response to interaction and wider adaptation to the test environments followed by TOLE and BERENE, with their relative IPC1 scores closer to zero. Genotypes, CI-1525 x OMEGA/14Y and CI$1525 \times$ OMEGA/1Y demonstrated large and positive IPC1 scores and found relatively well adapted to Bekoji 2008 and Bekoji 2009 with larger and same sign IPC1 scores. On the other hand, genotype CHILALLO x OMEGA/4B with larger negative IPC1 score demonstrated better performance at Kulumsa 2008 (Fig. 1). 


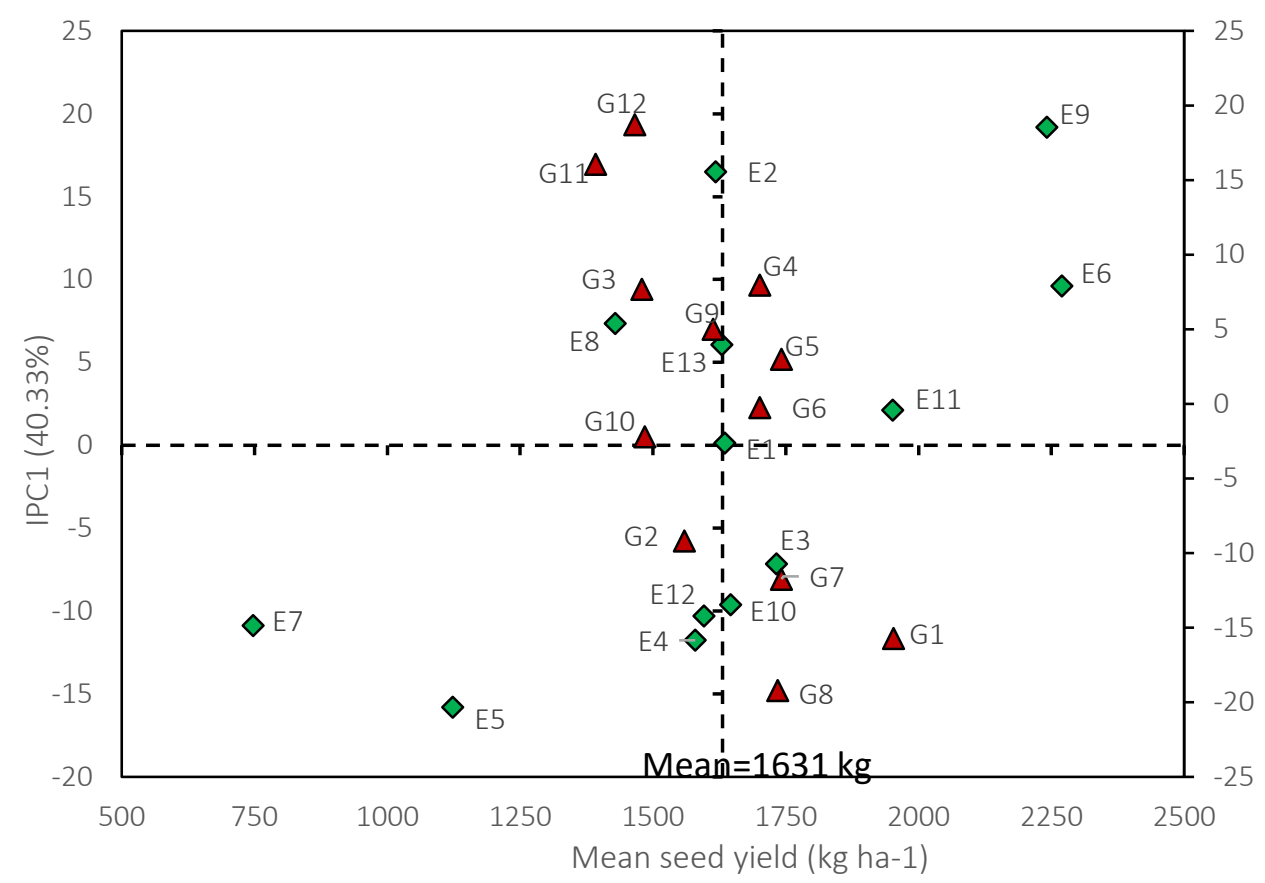

Figure 1. AMMI biplot showing the main (main effect) vs stability (IPC1) view of both genotypes and environments on seed yield. Abbreviations of genotypes and environments are as shown in Table 4.

AMMI 2 Biplot Display: AMMI2 biplot (Figure 2) was generated using genotypic and environmental scores of the first two AMMI multiplicative components to crossvalidate the interaction pattern of the 12 linseed genotypes within 13 environments. Connecting vertex cultivars markers in all direction form a polygon, such that all genotypes are contained within the polygon and a set of straight lines that radiate from the biplot origin to intersect each of the polygon sides at right angles form sectors of genotypes and environments (Yan, 2011). Based on AMMI2, a biplot with five sections are formed depending upon signs of the genotypic and environmental IPC scores. The test environments were grouped into four of the sections but the majority of the environments (11 out of thirteen) were grouped only within two of the sectors (Figure 3). Each of Bekoji and Holeta in both years clustered in the same but separate sectors indicating repeatable performance of the genotypes observed in these locations and they could be considered as separate mega-locations for linseed variety evaluation and recommendation. The distances from the origin $(0,0)$ are indicative of the amount of interaction that was exhibited by genotypes either over environments or environments over genotypes (Thangavel et al., 2011; Yan and Tinker, 2006). In this case, CI-1525 x OMEGA/14Y, CHILALLO $\mathrm{x}$ PGRCE10306/4Y, CI-1525, CHILALLO x OMEGA/4B and
KULUMSA-1 (Figure 2) expressed either positively or negatively high interactive behavior and believed contributed more to the exhibited $\mathrm{G} \times \mathrm{E}$ interaction whereas Asasa 2008 was the least interactive of all the environments against Meraro 2008 which was the most interactive of all the environments. Genotypeenvironment affinity depicted as orthogonal projections of the genotypes on the environmental vectors to identify the best genotype with respect to environments and the vertex genotypes in each sector are considered best at environments whose markers fall into the respective sector. In other words, environments within the same sector are assumed to share the same winner genotypes. In this regard, the best genotype with respect to environments Holeta 2008, Kofele 2008, Arsi Robe 2009, Holeta 2009 and Meraro 2009 was CHILALLO x OMEGA/4B and this genotype was later released as a variety and named Bakalcha (MoANR, 2016) for commercial production in Arsi, West Arsi Zones and similar agro-ecologies. Likewise, the best adapted genotype for the environments; Bekoji 2008, Bekoji 2009, Asasa 2009, Kulumsa 2009 and Sagure 2009 was CI-1525 x OMEGA/14Y. On the other hand, genotypes like CI-1652 and KULUMSA-1 fall in sectors where there were no environments at all; indicating their poor adaptation to any of the testing environments in those growing periods. 


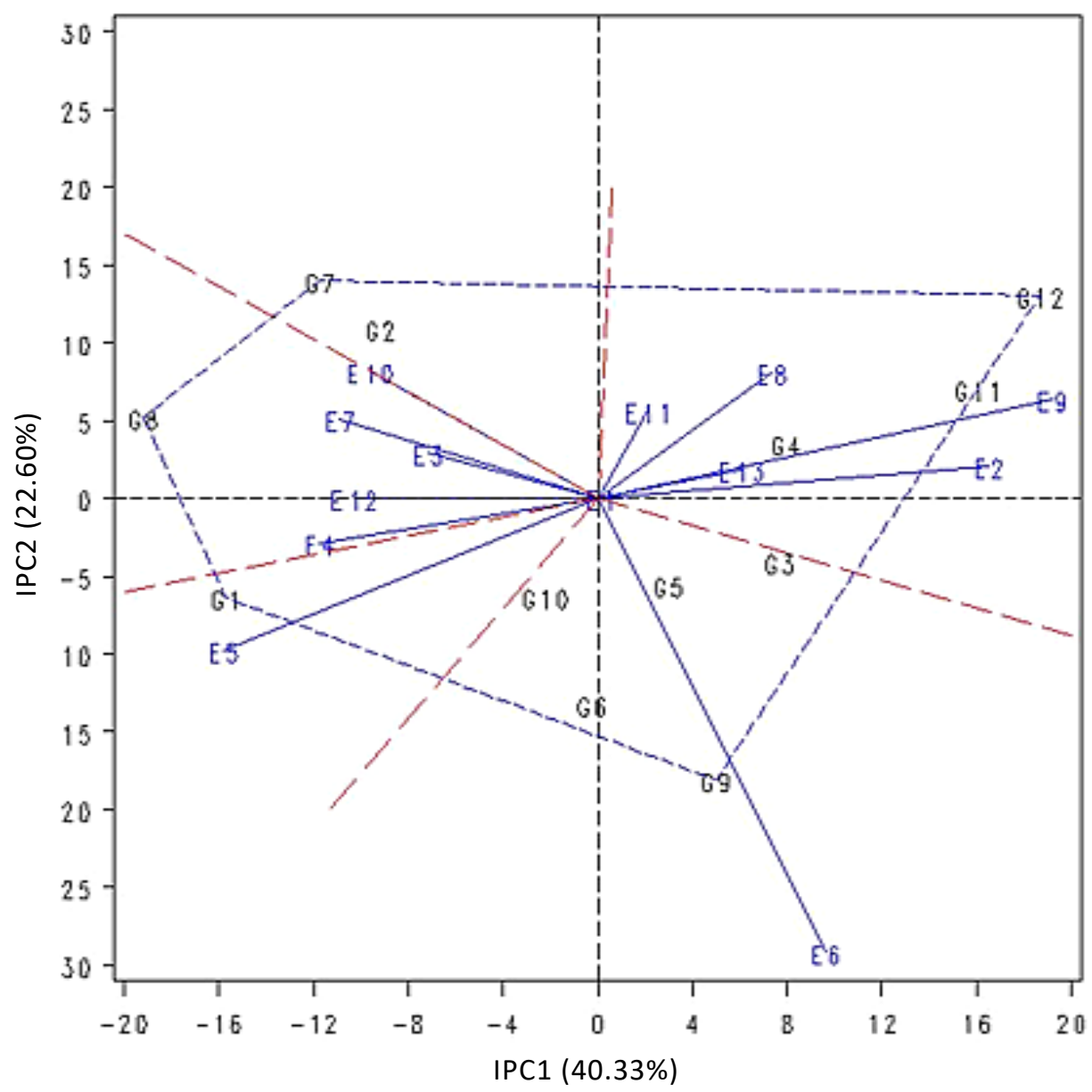

Figure 2. AMMI biplot analysis showing the mega-environments and their respective high yielding genotypes. Abbreviations of genotypes and environments are as given in Table 4.

SREG GGE Biplot Analysis: The GGE refers to the genotype main effect (G) plus the genotype-byenvironment interaction (GE), which are the two sources of variation of the site regression (SREG) model (Ding et al., 2007; Yan et al., 2007). GGE biplot best fits for whichwon-where pattern analysis, genotype, and test environment evaluation (Yan et al., 2007). The partitioning of GGE through GGE biplot analysis for the 12 linseed genotypes in 13 environments showed that PCA 1 and PCA 2 accounted for $53.63 \%$ and $15.57 \%$ of GGE sum of squares respectively for seed yield, explaining a total of $69.2 \%$ variation as shown in Fig. 3. Environment interaction principal component scores (IPC1 and IPC2) of GGE also had both positive and negative values in the present data set (Fig. 3) indicating the presence of rank order changes with changes in environments for yield performance among the linseed genotypes, leading to a crossover type of GEI. The same result has been reported on 14 field pea genotypes evaluated in 16 environments in Ethiopia (Tolessa et al., 2013) The requirement of "near-perfect correlation" ( $\mathrm{r}=0.95)$ between genotype IPC1 scores and genotype main effects (Ding et al., 2007; Yan and Hunt, 2001; Yan and Rajcan, 2002), which commonly occurs when genotype sum of square is $40 \%$ or more of GGE sum of squares (Yan et al., 2000) has been closely met in the present dataset (i.e., $r=0.96$ or genotype sum of square $=36.5 \%$ of GGE sum of squares). Therefore, the yielding ability and stability of genotypes, and discriminating ability and representativeness of the test environments can be effectively visualized using the sites regression GGE biplots. In this study, the GGE biplots of SREG analysis depicted the relationship between the testing environments based on the angles between the vectors of the environments (Fig. 3), and the possibility for ranking of genotypes relative to the highest yielding environment (Fig.4). 
Relationships Among Test Environments: The environment vector view of GGE biplot (Fig.3) presents a summary of the interrelationships among the environments. The test environments are connected to the biplot origin by lines called environment vectors. The angle between the vectors of the two environments is related to the correlation coefficient between them. The cosine of the angles between environment vectors show relationships between test environments with acute angles indicating a strong positive correlation, obtuse angles strong negative correlation or cross over GEI of genotypes, and right angle showing no correlation (Yan and Tinker, 2006). A short vector may indicate that the test environment is not related to other environments (Yan, 2002). Accordingly, six of the thirteen environments, namely Holeta (2008 and 2009), Arsi Robe 2009, Asasa 2009, Kulumsa 2009 and Meraro 2009 were grouped in the same quadrant (quadrant II) indicating their positive correlation among each other based on the angle between them being less than $90^{\circ}$. Even though Kofele 2008, Kulumsa 2008 and Sagure 2009 were grouped together with Meraro 2008 in quadrant I, they are more closely related to those grouped in quadrant II since their angle with Meraro 2008 were wider as compared with their angle with those environments grouped in quadrant II. A presence of close positive associations between these testing environments is an indication that similar information could be obtained about the genotypes from a fewer test environment and that is considered as an opportunity to reduce costs of germplasm evaluation when resources are scanty (Yan and Tinker, 2006). Bekoji 2008 and Bekoji 2009 had an acute angle and were positively correlated. They were grouped separately in quadrant IV and both had an obtuse angle with the rest of the environments except with that of Meraro 2008 indicating their negative correlation and the existence of cross-over GEI. The short vector view of Asasa 2008 indicates its un-relatedness to any of the test environments. The length of the environmental vector is also indicative of the discriminating ability of the test environment (Yan and Tinker, 2006). The longer the environment vectors length the more discrimination among the test genotypes and vice versa. Thus, six of the thirteen test environments including, Kofele 2008, Kulumsa 2008, Meraro 2008, Arsi Robe 2009, Holeta 2009 and Meraro 2009 most discriminated the tested genotypes whereas, Asasa least discriminated the genotypes in both years.

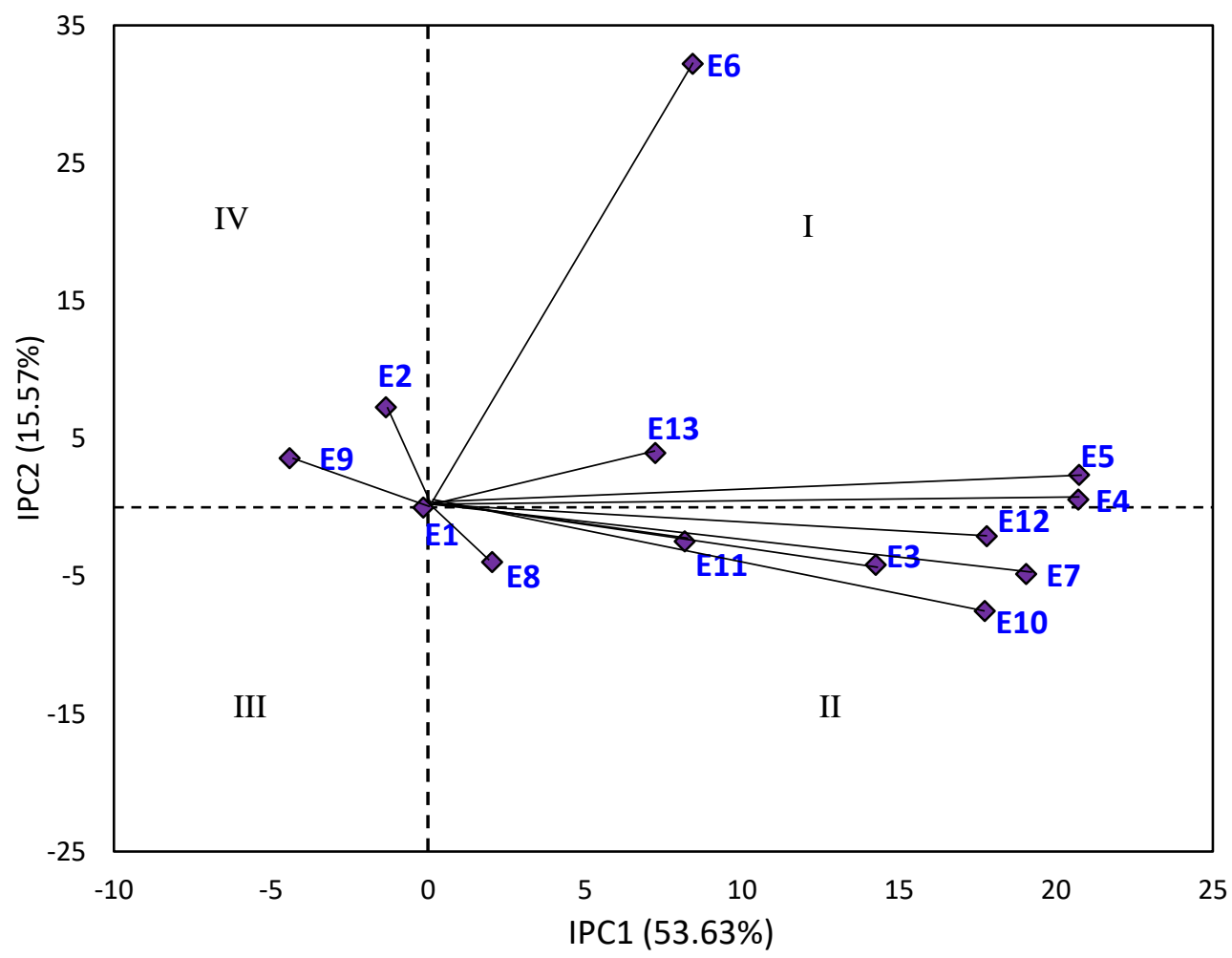

Figure 3. Vector view of GGE from SREG for thirteen test environments. Abbreviations of environments as given in Table 4. 
Ranking of Genotypes Relative to Highest Yielding Environment: A line that passes through the biplot origin and the highest yielding environment was drawn to help ranking the genotypes based on their performance in an environment, and this line is called the highest yielding environment axis (Yan and Tinker, 2006). Fig. 4 illustrates the graphics comparison of the relative performance of the 12 linseed genotypes relative to the highest yielding environment, Meraro 2008. Genotypes located on the right-hand side of the perpendicular line to Meraro 2008-axis, namely CI-1525, BELAY-96, BERENE and TOLE showed higher than average yield. Those genotypes located on the left-hand side of the perpendicular line to the Meraro 2008-axis such as CI-1652, CHILALLO, CHILALLO x OMEGA/13Y, CI-1525 $\mathrm{x}$ OMEGA/1Y and CI-1525 $\mathrm{x}$ OMEGA/14Y showed lower than average yield. However, genotypes KULUMSA-1 and CHILALLO x OMEGA/4B demonstrated above average yield performance in the test environments (Table 4) but ranked in the below average side of the biplot (Fig. 5); on the other hand, CHILALLO $\mathrm{x}$ PGRCE10306/4Y demonstrated below average yield performance but ranked in the above average side of the biplot revealing that the SREG GGE was not $100 \%$ efficient in exhibiting the existing $\mathrm{G} \times \mathrm{E}$ interaction in the present linseed genotypes dataset.

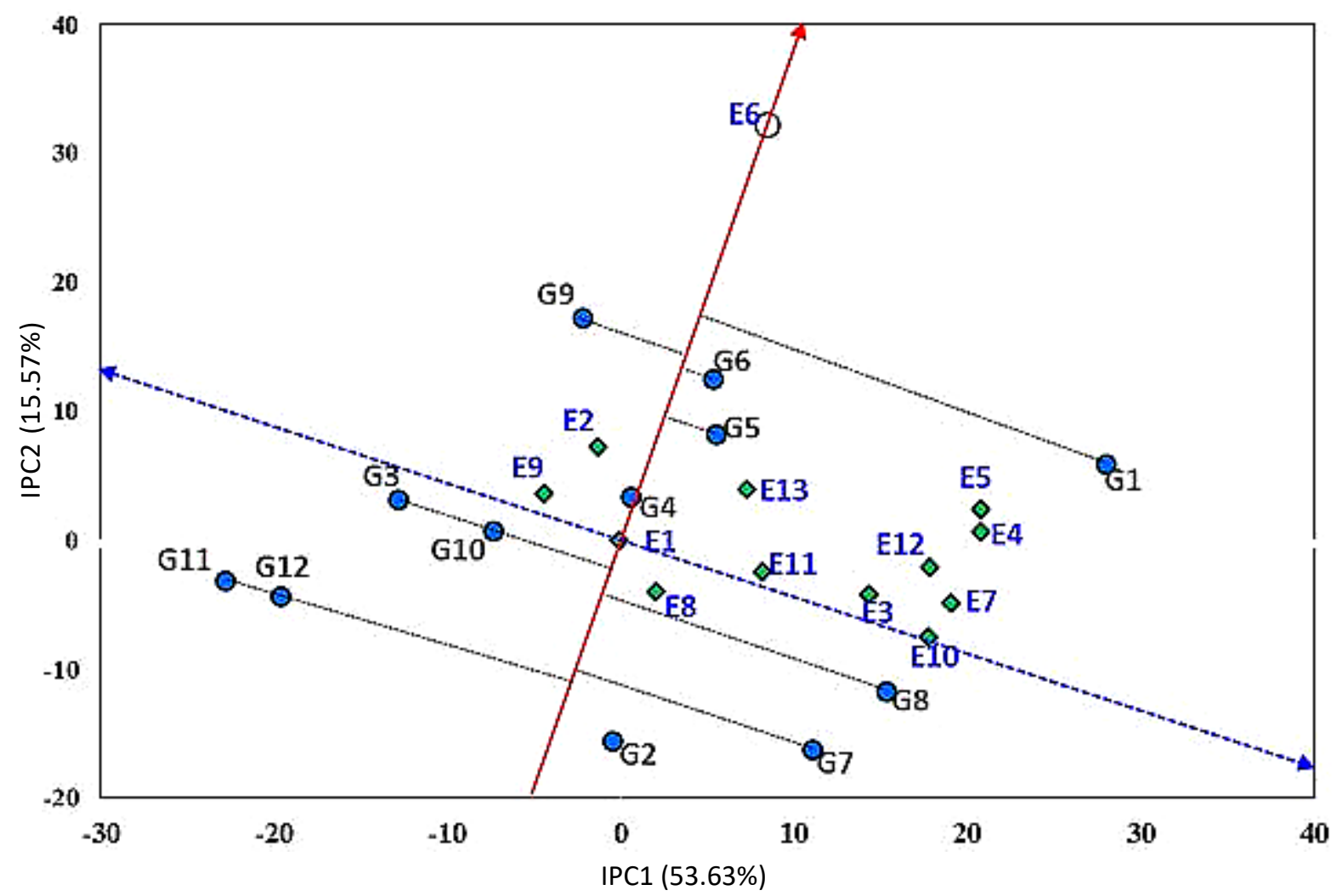

Figure 4. GGE from SREG for ranking of all genotypes relative to the test environment with highest yielding performance (in this case: Meraro 2008). Abbreviations of genotypes and environments are as given in Table 4.

\section{CONCLUSIONS}

The present study revealed that linseed yields were liable to a significant fluctuation with changes in the growing environments, the $\mathrm{G} \times \mathrm{E}$ interaction effect being almost two times higher than that of the genotype effect. This study also clearly demonstrated that AMMI and SREG GGE models were found to be effective for determining the magnitude and pattern of genotype $\times$ environment interaction effects in the linseed genotypes.
Even though no variety showed a universally superior performance across all the test environments, one variety (CI-1525) showed consistently better mean performance at six of the thirteen environments. Vertex genotypes including CI-1525 x OMEGA/14Y, CHILALLO $\mathrm{x}$ PGRCE10306/4Y, CI-1525, CHILALLO x OMEGA/4B and KULUMSA-1 expressed either higher positive or negative interactive behaviour and believed contributed more to the exhibited $\mathrm{G} \times \mathrm{E}$ interaction. Other genotypes such as 
CHILALLO x OMEGA/13Y, TOLE and BERENE with IPC1 scores close to zero exhibited relatively better general adaptation and lesser response to the interaction. There were close positive associations between some of the testing environments suggesting a possibility of obtaining similar information about linseed genotypes from a fewer test environment and that is considered as an opportunity to reduce costs of germplasm evaluations. Six of the thirteen test environments including, Kofele 2008, Kulumsa 2008, Meraro 2008, Arsi Robe 2009, Holeta 2009 and Meraro 2009 most discriminated the tested genotypes whereas, Asasa least discriminated the genotypes in both years.

\section{ACKNOWLEDGEMENTS}

The authors would like to acknowledge the financial support provided by the Ethiopian Institute of Agricultural Research for conducting field trials. We would like to express our great gratitude to Highland Oil Crops Research Program Staffs of Kulumsa and Holetta Agricultural Research Centers for their support in field trials management and data collection. The authors would also like to thank Mr. Tamene Tolessa for his support in data analysis.

\section{REFERENCES}

Abebe, D. and C. Adane. 2015. Response of linseed (Linum usitatissimum L.) to seed rates and seeding methods in South-Eastern highlands of Ethiopia. Journal of Biology, Agriculture and Healthcare, 5: 218-223.

Adugna, W. and M. T. Labuschagne. 2002. Genotypeenvironment interactions and phenotypic stability analyses of linseed in Ethiopia. Plant Breeding, 121: 66-71.

Adugna, W. and M. T. Labuschagne. 2003. Parametric and non-parametric measures of phenotypic stability in linseed (Linum usitatissimum L.) in Ethiopia. Euphytica, 129: 211-218.

Altai, F. 2010. Flax Seed Cak. Scientific and Production Association 'Altai Flax' LLC, Russia.

Bantayehu, G. 1965. Progress Report on Cereals, Oilseeds and Pulses. Experimental Station Bull No. 64. Haramaya University, Dire Dawa, Ethiopia.

Berti, M., S. Fischer, R. Wilckens, F. Hevia and B. Johnson. 2010. Adaptation and genotypex environment interaction of flaxseed (Linum usitatissimum L.) genotypes in South Central Chile. Chilean Journal of Agricultural Research, 70: 345-356.

Burgueño, J., J. Crossa and M. Vargas. 2001. SAS programs for graphing GE and GGE biplots. CIMMYT, Intl., Mexico.

CSA. 2016. Agricultural sample survey report on area and production of crops. Central Statistical Agency of Ethiopia. Stat. Bul. , 1.

Dehghani, H., N. Sabaghnia and M. Moghaddam. 2008. Interpretation of Genotype-by-environment Interaction for Late Maize Hybrids' Grain Yield Using a Biplot Method. Turkish Journal of Agriculture and Forestry, 33: 139-148.

Ding, M., B. Tier and W. Yan. 2007. Application of GGE Biplot Analysis to Evaluate Genotype Environment and GxE interaction on P. radiata. Australasian Forest Genetics Conference. The Old Wool Store.

Ebdon, J. S. and H. G. Gauch. 2002. Additive Main Effect and Multiplicative Interaction Analysis of National Turfgrass Performance Trials. Crop Science, 42: 489-496.

Ersullo, L., Z. Habtamu and W. Adugna. 2016. AMMI Analysis of Yields and Oil Content in Some Linseed (Linum usitatissimum L.) Genotypes in South and Central Ethiopia. Ethiopian Journal of Agricultural Sciences, 24: 79-98.

Gauch, H. G. 1988. Model Selection and Validation for Yield Trials with Interaction. Biometrics, 44: 705715.

Gauch, H. G. and R. W. Zobel. 1997. Identifying MegaEnvironments and Targeting Genotypes. Crop Science, 37: 311-326.

Getinet, A. and A. Nigussie. 1997. Highland Oil Crops: A Three-Decade Research Experience in Ethiopia. Research Report No. 30. Ethiopian Institute of Agricultural Research, Addis Ababa, Ethiopia.

Grüneberg, W. J., K. Manrique, D. Zhang and M. Hermann. 2005. Genotype $\times$ Environment Interactions for a Diverse Set of Sweetpotato Clones Evaluated across Varying Ecogeographic Conditions in Peru. Crop Science, 45: 2160-2171.

Hernandez, M. V. and J. Crossa. 2000. The AMMI analysis and graphing the biplot. Biometrics and Statistics Unit, CIMMYT, Mexico.

Jacobsz, M. J., W. J. C. V. Merwe and M. M. V. Westhuizen. 2015. Additive Main Effects and Multiplicative Interaction Analysis of European Linseed (Linum Ustatissimum L.) Cultivars under South African Conditions. Advances in Plants \& Agriculture Research, 2: 120-124.

Kaya, Y., M. Akçura and S. Taner. 2006. GGE-biplot 
analysis of multi-environment yield trials in bread wheat. Turkish Journal of Agriculture and Forestry, 30: 325-337.

Kempton, R. A. 1984. The use of biplots in interpreting variety by environment interactions. The Journal of Agricultural Science, 103: 123-135.

Lay, C. L. and C. D. Dybing. 1989. Linseed, In: G. Robbelin \& R. K. Downey \& A. Ashri, (eds.), Oil Crops of the World. McGraw-Hill, New York.

Ma, B. L., W. Yan, L. M. Dwyer, J. Fregeau-Reid, H. D. Voldeng, Y. Dion and H. Nass. 2004. Graphic analysis of genotype, environment, nitrogen fertilizer, and their interactions on spring wheat yield. Agronomy Journal, 96: 169-180.

MoANR. 2016. Plant variety release, protection and seed quality control. Crop Variety Register. Issue No. 18. Ministry of Agriculture and Natural Resource, Addis Ababa, Ethiopia.

Navabi, A., R.-C. Yang, J. Helm and D. M. Spaner. 2006. Can Spring Wheat-Growing Megaenvironments in the Northern Great Plains Be Dissected for Representative Locations or Niche-Adapted Genotypes? Crop Science, 46: 1107-1116.

SAS. 2002. Statistical Analysis Software Version 9., SAS/STAT Guide for Personal Computers. SAS Institute Inc., Carry, NC. United States.

Tadesse, T. 2017. AMMI Model for Yield Stability Analysis of Linseed Genotypes for the Highlands of Bale, Ethiopia. Plant, 5: 93-98.

Thangavel, P., A. Anandan and R. Eswaran. 2011. AMMI analysis to comprehend genotype-byenvironment $(G \times E)$ interactions in rainfed grown mungbean (Vigna radiata L.). Australian Journal of Crop Science, 5: 1767-1775.

Tolessa, T. T., G. Keneni, T. Sefera, M. Jarso and Y. Bekele. 2013. Genotypex environment interaction and performance stability for grain yield in field pea (Pisum sativum L.) genotypes. International
Journal of plant breeding, 7: 116-123.

Vaisey-Genser, M. and D. H. Morris. 2010. Flaxseed: Health Nutrition and Functionality. Flax Council of Canada, Winnipeg, Manitoba, Canada.

Yan, W. 2002. Singular-value partitioning in biplot analysis of multi-environment trial data. Agronomy Journal, 94: 990-996.

Yan, W. 2011. GGE Biplot vs. AMMI graphs for genotypeby-environment data analysis. Journal of the Indian Society of Agricultural Statistics, 65: 181193.

Yan, W., P. L. Cornelius, J. Crossa and L. A. Hunt. 2001. Two Types of GGE Biplots for Analyzing MultiEnvironment Trial Data. Crop Science, 41: 656663.

Yan, W. and L. A. Hunt. 2001. Interpretation of Genotype $\times$ Environment Interaction for Winter Wheat Yield in Ontario. Crop Science, 41: 19-25.

Yan, W., L. A. Hunt, Q. Sheng and Z. Szlavnics. 2000. Cultivar Evaluation and Mega-Environment Investigation Based on the GGE Biplot. Crop Science, 40: 597-605.

Yan, W. and M. Kang. 2003. GGE Biplot Analysis: A Graphical Tool for Breeders, Geneticists, and Agronomists. CRC Press, Boca Raton, FL, p. 288.

Yan, W., M. S. Kang, B. Ma, S. Woods and P. L. Cornelius. 2007. GGE Biplot vs. AMMI Analysis of Genotypeby-Environment Data. Crop Science, 47: 643-655.

Yan, W. and I. Rajcan. 2002. Biplot Analysis of Test Sites and Trait Relations of Soybean in Ontario. Crop Science, 42: 11-20.

Yan, W. and N. A. Tinker. 2006. Biplot analysis of multienvironment trial data: Principles and applications. Canadian Journal of Plant Science, 86: 623-645.

Zobel, R. W., M. J. Wright and H. G. Gauch. 1988. Statistical Analysis of a Yield Trial. Agronomy Journal, 80: 388-393. 